WellBeing International

WBI Studies Repository

2008

\title{
Lack of Assortative Mating Between Incipient Species of Stickleback from a Hybrid Zone
}

\author{
F. C. Jones \\ University of Edinburgh \\ C. Brown \\ University of Edinburgh \\ V. A. Braithwaite \\ University of Edinburgh
}

Follow this and additional works at: https://www.wellbeingintlstudiesrepository.org/evobio

Part of the Animal Studies Commons, Other Animal Sciences Commons, and the Other Ecology and Evolutionary Biology Commons

\section{Recommended Citation}

Jones, F. C., Brown, C., \& Braithwaite, V. A. (2008). Lack of assortative mating between incipient species of stickleback from a hybrid zone. Behaviour, 145(4), 463-484.

This material is brought to you for free and open access by WellBeing International. It has been accepted for inclusion by an authorized administrator of the WBI Studies Repository. For more information, please contact wbisr-info@wellbeingintl.org.

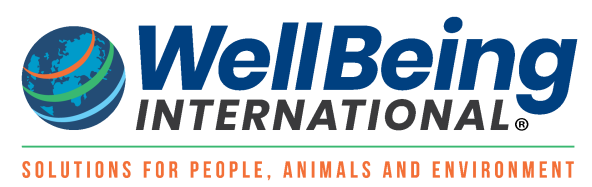




\title{
Lack of Assortative Mating Between Incipient Species of Stickleback from a Hybrid Zone
}

\author{
F.C. Jones, C. Brown, and V.A. Braithwaite \\ University of Edinburgh
}

\begin{abstract}
KEYWORDS
threespined stickleback, Gasterosteus aculeatus, assortative mating, speciation, hybridisation, microsatellite, sexual selection, reproductive isolation
\end{abstract}

\begin{abstract}
Both premating and postmating barriers to gene flow can contribute to reproductive isolation but the relative role of these factors, particularly in the early stages of speciation, is not well understood. Evidence suggests that factors contributing to assortative mating and, thus, the development and maintenance of divergent species, can be ecologydependent. Here, we present results from a study of assortative mating between recently diverged anadromous and freshwater sticklebacks conducted in semi-natural conditions. Sympatric anadromous and freshwater sticklebacks were sampled from a contact zone and multiple male and female morphs were allowed to breed in replicate ponds. Mate choice was determined using genetic markers to assign parents to offspring. Contrary to laboratory-based studies of sticklebacks, after allowing for differences in the propensity of the morphotypes to mate, we found no evidence of assortative mating. Furthermore, there was no evidence of size assortative mating, but rather a general female 'preference' to mate with large males was revealed. Analysis of the propensity of different morphotype combinations to produce fry provided indirect evidence that exogenous factors may influence hybrid survival. Our results indicate that hybridization between anadromous and freshwater sticklebacks from the River Tyne, Scotland, occurs readily, and that sexual selection is unlikely to contribute to premating isolation. From these results we infer that postmating isolation (hybrid inferiority) has preceded the evolution of premating isolation (assortative mating) in this population of sticklebacks.
\end{abstract}

\section{Introduction}

Under the Biological Species Concept (Mayr, 1942), species are defined as groups of actually or potentially interbreeding organisms reproductively isolated from other such groups. Thus, the process of speciation involves the evolution of reproductive isolating barriers. Identifying barriers to gene flow between diverging populations can provide insight on mechanisms driving reproductive isolation and speciation. Following the framework laid down by Dobzhansky (1951) and Mayr (1942) these barriers fall into two broad groups: premating barriers which act to limit the formation of zygotes, and postmating barriers which act to reduce the fitness of hybrid offspring. Assortative mating, the occurrence of matings within forms more often than between forms, can be the outcome of multiple different premating barriers and, therefore, is a useful way of quantifying premating reproductive isolation. Commonly studied premating barriers such as divergent mate choice, spatial and/or temporal differences in breeding 
season, or less well studied premating barriers such as immigrant inviability (Nosil et al., 2005), or intersexual competition for resources may all contribute towards positive assortative mating.

Studies of contact zones between divergent populations can provide important insight into the strength of premating reproductive isolation and speciation (McMillan et al., 1997; Bailey et al., 2004; Cruz et al., 2004; Patten et al., 2004). In the case of hybrid zones, the area of sympatry provides the immediate ecological context in which factors other than spatial separation can drive reproductive isolation, although the environment experienced by migrants prior to dispersing into the zone may also play a role. Incipient species provide an excellent opportunity to investigate the importance of different reproductive isolating barriers because the nature of the divergence is not obscured by differences which have accumulated after reproductive isolation evolved.

In this respect, stickleback species pairs (e.g., limnetic-benthic, anadromous-freshwater) are model organisms for studies of speciation (McKinnon \& Rundle, 2002). During an adaptive radiation, anadromous and freshwater sticklebacks evolved repeatedly and independently from a common marine ancestor (McPhail, 1994; McKinnon et al., 2004). These morphs vary in numerous traits including life history, morphology, behaviour, and genetic composition (McPhail, 1994). Obvious divergent morphological traits include body size and lateral plate number with anadromous morphs being larger and possessing complete sets of lateral plates compared to the smaller, low plated freshwater morphs (McPhail, 1994). Contact zones between anadromous and freshwater sticklebacks occur along environmental gradients (lower reaches of rivers and estuaries) and the occurrence of both morphotypes in sympatry provides an excellent opportunity to examine the nature of reproductive isolation.

Assortative mate choice is likely to contribute to premating isolation between anadromous and freshwater sticklebacks, and many studies have investigated this possibility (Hagen, 1967; Hay \& McPhail, 1975; Ziuganov, 1995; Ishikawa \&Mori, 2000; McKinnon et al., 2004; Scott, 2004), although experimental approaches have varied. The presence of sexual dimorphism is indicative of sexual selection, and male sticklebacks display costly secondary sexual traits (Hill, 1999). Female sticklebacks show a preference for a number of different male traits such as red colouration (Milinski \& Bakker, 1990), blue eye colour, MHC alleles (Reusch et al., 2001) and larger body size (Rowland, 1989a). Choosiness in females may be rewarded by fitness benefits such as superior paternal care (McKinnon, 1996) and good genes (e.g., Barber et al., 2001). Males may also be choosy and will court larger females when given a choice (Kraak \& Bakker, 1998).

A common approach in investigating premating reproductive isolation is to focus on one potential barrier by conducting experiments under laboratory conditions to exclude the effects of assortative mating resulting from other premating barriers. For example, numerous studies have investigated whether divergent mate choice contributes significantly to reproductive isolation by controlling for reproductive readiness (timing) and excluding competitive interactions. However, the particular premating barrier under consideration in the laboratory may be obscured or less relevant in the wild where multiple ecological factors come into play. For example, divergent bidirectional mate choice may be present in the laboratory but uni-directional in the wild because territorial exclusion of one morphotype limits mate choice options. Both theoretical and empirical work support the notion that the strength and nature of premating reproductive isolation can vary depending on the ecological context (Endler, 1992; Kirkpatrick \& Ravigne, 2002). For example, recent studies suggest that divergent mate choice is often ecology-dependent (e.g., host plant specialisation in pea aphids - Acyrthosiphon pisum (Caillaud \& Via, 2000); sexual selection based on ecologically divergent traits in sticklebacks (McKinnon et al., 2004; Boughman et al., 2005); song-type in song sparrows - Melospiza melodia (Patten et al., 2004)). In addition, physical differences in the laboratory environment may affect signalling, perception, and mating behaviour (e.g., Houde \& Endler, 1990), and prior experience of ecological conditions such as predation regime, food availability 
and familiarity with potential mates may also affect an individual's mating behaviour (Kelley et al., 1999; Haavie et al., 2004; Ward et al., 2004). The dependence of mate choice on both past and present ecological and physical contexts highlights the importance of experimental design from which conclusions about the strength of premating reproductive isolation are drawn.

Evidence suggests that assortative mate choice is based on ecologically divergent traits and is important in maintaining differences between stickleback species pairs (McKinnon et al., 2004; Boughman et al., 2005). In different species pairs (limnetic-benthic, anadromous-freshwater), one theme is emerging: assortative mating based on body size explains a large amount of the variation seen in mate choice. Hybridisation between limnetic and benthic sticklebacks occurred only between the larger individuals of the smaller species and smaller individuals of the larger species (Nagel \& Schluter, 1998). In a landmark study, McKinnon and colleagues (2004) were able to uncouple body size from other morphological traits by manipulating rearing conditions and found that mating 'incompatibilities' between pairs of anadromous and freshwater sticklebacks were largely explained by differences in body size, although preference for own morphotype still remained significant.

Previous studies of assortative mate choice between anadromous and freshwater sticklebacks have neglected the importance of ecological context on assortative mating, thus potentially obscuring the relative strength and importance of premating isolating mechanisms. For example, many studies used morphs collected from allopatric rather than sympatric populations (e.g., McPhail \& Hay, 1983; Ishikawa \& Mori, 2000; McKinnon et al., 2004; Scott, 2004). Sampling individuals from either side of the contact zone may avoid problems associated with misidentification of morphotypes within the zone, and excludes the possibility of reinforcement (Dobzhansky, 1951) driving divergence in mate choice, but it makes the assumption that mating behaviour is independent of the environment individual's experience. Furthermore, the strength of assortative mating displayed by individuals from allopatric populations may not reflect the behaviour of individuals or the degree of reproductive isolation in hybrid zones (e.g., Gee, 2003). For example, assortative mating between fire-bellied toads (Bombina bombina and B. variegata) was stronger outside than within the hybrid zone (Szymura \& Barton, 1986) and significant assortment between some geographically isolated populations of the same subspecies has been found in grasshoppers (Chorthippus parallelus, Butlin, 1998). Alternatively, stronger assortative mating might occur in sympatry than allopatry. For example, due to reinforcement (Rundle \& Schluter, 1998), or learned mate recognition (Magurran \& Ramnarine, 2004).

The design of some studies investigating mating behaviour of sticklebacks restricts the nature of interpretations that can be made regarding the importance of premating isolation. For example, recent developments in signal-receiver literature (e.g., Peake \& McGregor, 2004) call into question the utility of dichotomous choice tests that focus on female choice (e.g., Hagen, 1967; Hay \& McPhail, 1975; Ziuganov, 1995; McKinnon et al., 2004). Experimental designs allowing for interactions in a social network (e.g., between multiple males and females) rather than staged dyadic interactions may more accurately reflect mate choice in the wild where hierarchies, access to mates, and male choice are likely to be important (Reichard et al., 2005). Finally, some experiments used behavioural indicators of mate choice such as female 'head up' posture (Hagen, 1967) or nest inspection (McKinnon et al., 2004) which may not be reliable indicators of mate choice. Conducting a study of assortative mating in a natural population, however, would also be difficult because of problems in identifying the individuals present. Ideally, in order to study the strength of assortative mating and the extent of premating isolation between divergent morphs, it is necessary to utilise individuals collected from a site where they exist in sympatry, where these individuals are allowed to choose between multiple mates that are freely interacting, and use successful mating events as an indicator of mating. 
In this study, we examine the strength of premating isolation between anadromous and freshwater morphs of the threespine stickleback. We test for assortative mating using sticklebacks collected from the same site in the River Tyne, Scotland, where the morphotypes breed in both spatial and temporal sympatry. Our primary aim was to determine whether hybridization and/or assortative mating occur when anadromous and freshwater sticklebacks breed in sympatry. We set out to address three specific questions: (i) Does assortative mating based on morphotype occur? (ii) Is assortative mating influenced by body size? (iii) Is there evidence of hybrid inferiority?

\section{Materials and methods}

\section{Sample collection and experimental design}

In May 2002, adult sticklebacks were trapped at a freshwater site on the River Tyne, East Lothian, Scotland $\left(55^{\circ} 59.5^{\prime} \mathrm{N} 2^{\circ} 37.8^{\prime} \mathrm{W}\right)$. The peak breeding seasons of anadromous and freshwater sticklebacks in this site overlaps in the months of May and June (Jones et al., 2006). Fish were sorted using morphological criteria into (i) olive-green, small, low plated, keel absent 'freshwater' morphs, (ii) silver, high plated, large, keel present 'anadromous' morphs or (iii) 'hybrid' morphs with mixed combinations of these traits. 65 freshwater and 65 anadromous fish were transported to the University of Edinburgh where no more than 10 fish of the same morphotype were housed in 40 litre tanks.

After three weeks, 16 individuals of each sex and morphotype (64 fish total) were photographed against a $5 \mathrm{~mm}$ grid and fin-clipped for genetic analysis. Standard length was measured from analysis of digital photographs and was used as a measure of individual body size. To ensure correct sex identification and reproductive readiness, fish were chosen on the basis of their secondary sexual characteristics (gravidity of females, red throat and blue eye colouration of males). Individuals were placed into four outdoor ponds; each pond received four males and four females of both anadromous and freshwater morphotypes (16 fish total per pond). The ponds ( $3 \mathrm{~m} \mathrm{~L} \times 2 \mathrm{~m} \mathrm{~W} \times 1 \mathrm{~m} \mathrm{D}$ ) were devoid of fish, and they contained a gravel and sand substrate with two species of aquatic plant (Potamogeton spp. and Zannichellia spp). One month after the adults were released into the ponds, 100 fry (approximately 10 $\mathrm{mm}$ size) from each pond were sampled one at a time in an opportunistic fashion.

\section{Genotyping}

DNA was extracted from finclips of adults and fry using a Chelex extraction protocol (Walsh et al., 1991) with $0.8 \mu \mathrm{g} / \mu \mathrm{l}$ proteinase $\mathrm{K}$. Fish were genotyped at eight microsatellite loci (Appendix A).

\section{Parentage assignment}

We used the maximum likelihood algorithm of the PAPA software (Duchesne et al., 2002) for parentage assignment. Initially, we tested the power of our eight markers to correctly allocate offspring to parents by performing simulations using the 32 male and 32 female real-parental genotypes were to generate 400 pseudo-offspring genotypes. Then pseudo-offspring were allocated to parents using the likelihood method and this process was iterated 5000 times (Appendix $\mathrm{C}$ ). The mean proportion of offspring assigned to the correct parents was 0.996 ( $\pm 0.003 \mathrm{SD}$ ), indicating a very high allocation success. Genotypes of the 100 fry and 16 potential parents from each pond were then used to allocate each offspring a male and female parent from that pond. 


\section{Statistical analyses}

Female mating behaviour

For each female adult we calculated two variables: (i) the number of different mating partners detected and (ii) the number of fry sampled. We tested for differences in these variables between female morphotypes using linear mixed effect models which enabled us to estimate the added variance component explained by pond as a random effect (Sokal \& Rohlf, 1995; Zar, 1998). The mixed effect ANOVA approach partitions variation which might be explained by individuals within a pond sharing a similar environment.

\section{Likelihood models}

Within each pond and overall, we tested for evidence of morphotype-based assortative mating. Differences in the fecundity or propensity of anadromous and freshwater morphotypes to mate may obscure estimates of the strength of assortative mating. For this reason we used a likelihood approach, similar to that used by Davies et al. (1997), McMillan et al. (1997), Mallet et al. (1998) and Tregenza et al. (2000), to examine parental mating behaviour which enabled us to distinguish assortative mating from these effects. We performed this analysis twice using different variables. First, from the parental allocations, we calculated the number of distinct 'mating events' (defined as unique combinations of female and male parents). Multiple fry allocated the same parents were assumed to have resulted from a single mating event. In each of the four ponds, mating events were classified into one of the four possible parental morphotype combinations (see Table 1) and these data were analysed using a maximum likelihood approach (detailed below). Second, we repeated the analysis using the 'total number of fry' sampled from each of the parental morphotype combinations in each of the ponds (see Table 1).

Table 1. The number of mating events and the number of fry sampled from each of the parental morphotypes.

\begin{tabular}{|c|c|c|c|c|}
\hline Pond & $\begin{array}{l}\text { Anadromous } \\
\text { female- } \\
\text { Anadromous } \\
\text { male }\end{array}$ & $\begin{array}{l}\text { Anadromous } \\
\text { female- } \\
\text { Freshwater } \\
\text { male }\end{array}$ & $\begin{array}{l}\text { Freshwater } \\
\text { female- } \\
\text { Anadromous } \\
\text { male }\end{array}$ & $\begin{array}{l}\text { Freshwater } \\
\text { female- } \\
\text { Freshwater } \\
\text { male }\end{array}$ \\
\hline \multicolumn{5}{|l|}{ Mating events } \\
\hline A & 8 & 3 & 8 & 7 \\
\hline B & 8 & 6 & 2 & 1 \\
\hline C & 7 & 1 & 5 & 2 \\
\hline D & 5 & 7 & 0 & 2 \\
\hline \multicolumn{5}{|l|}{ Number of fry } \\
\hline A & 52 & 8 & 25 & 11 \\
\hline B & 53 & 15 & 15 & 9 \\
\hline C & 60 & 7 & 27 & 2 \\
\hline D & 36 & 35 & 0 & 17 \\
\hline
\end{tabular}


Under the full model, the probability of mating between morphotypes $\mathrm{i}$ and $\mathrm{j}$ was estimated allowing for differences in the propensity of alternative morphotypes to mate $\left(v_{\mathrm{j}}, v_{i}\right.$, males; $w_{j}, w_{i}$, females, ranging from 0 to 1$)$ and the existence of assortative mating $(I$, ranging from -1 (negative assortative mating) to +1 (positive assortative mating)),

$$
\begin{aligned}
& p_{\mathrm{ii}}=\left(\frac{v_{\mathrm{i}}}{\left(v_{\mathrm{i}}+v_{\mathrm{j}}\right)}\right)\left(\frac{w_{\mathrm{i}}}{\left(w_{\mathrm{i}}+w_{\mathrm{j}}\right)}\right)+I \\
& p_{\mathrm{ij}}=\left(\frac{v_{\mathrm{i}}}{\left(v_{\mathrm{i}}+v_{\mathrm{j}}\right)}\right)\left(\frac{w_{\mathrm{j}}}{\left(w_{\mathrm{i}}+w_{\mathrm{j}}\right)}\right)-I
\end{aligned}
$$

and so on for $p_{j i}$ and $p_{i i}$ (see Appendix D for more details).

In the analysis of the observed number of fry from each parental morphotype combinations, the parameters $\left(v_{\mathrm{FW}}\right.$ and $\left.w_{\mathrm{AN}}\right)$ represent the propensity to produce fry and might explain variation due to differences in the propensity to mate as well as differences in the fecundity of the morphotypes. Similarly, the assortative mating parameters $\left(I_{\mathrm{A}-\mathrm{D}}\right)$ might explain additional variation due to hybrid zygote and/or fry mortality.

The log likelihood of observed mating events or number of fry in a given pond (obs) can then be calculated as

$$
\log L=\sum_{\mathrm{ij}}(\mathrm{obs} * \ln (\exp p))
$$

where exp $p$ refers to the expected probability determined from parameter estimates in equation (1). The $\log L$ for each pond is summed to give the overall likelihood. By fixing the mating propensity of both anadromous males $\left(v_{\mathrm{AN}}\right)$ and females $\left(w_{\mathrm{AN}}\right)$ in each pond to 1 , we estimated the relative mating propensity of freshwater males $\left(v_{\mathrm{FW}}\right)$ and females $\left(w_{\mathrm{FW}}\right)$ and the assortative mating coefficient $(I)$. Parameter estimates were made by exploring all possible parameter values to identify those that returned the maximum likelihood for each pond. Thus, under the full model we estimated 3 parameters for each of the four ponds (12 parameters in total). We were unable to investigate asymmetrical assortative mating behaviour or distinguish between male and female choice due to lack of degrees of freedom. The maximum likelihood across all ponds was used to contrast different models (twice the difference in log likelihood between two models asymptotically follows a $\chi^{2}$ distribution (Edwards, 1972). Support limits for parameter values (asymptotically equivalent to $95 \%$ confidence intervals) were calculated by varying the parameter of interest until the likelihood dropped two units below the maximum, with all other parameters held constant.

Test for size assortative mating: parental body size

We performed an ANOVA to test for significant differences in standard length between parental morphotypes placed in each of the ponds. This was done using standard length as a dependent variable, and pond, morphotype and sex as independent factors. We then looked for evidence for size-based 
assortative mating by calculating, for each female, the mean standard length of males mated. An individual female's 'preference' for size was calculated as the difference in the mean size of males she mated and males she did not mate ( $>0$ mated with large males, $0=$ no preference, $<0$ mated with small males). We used a linear mixed effects model to explore whether female 'preference' for size was associated with female morphotype or female size (female morphotype and female standard length were entered as a fixed factor and covariate respectively, and pond as a random factor).

\section{Results}

\section{Parentage assignment}

$93 \%$ of the 400 offspring genotyped were allocated to parents. Individuals with ambiguous or no parental allocation were excluded from further analysis. We identified 41 of the 64 adults in the ponds as a parent of at least one fry. The sex, morphotype and the pond location of the 13 adults not identified as likely parents varied (Appendix B).

\section{Statistical analyses}

Female mating behaviour

More fry were sampled from anadromous females than from freshwater females and this difference approached significance (anadromous mean: $13.74 \pm 2.24 \mathrm{SE}$, freshwater mean: $9.40 \pm 2.24 \mathrm{SE}, p=$ 0.065 ; proportion of variance explained by pond $<0.001$ ). In addition, females that did reproduce mated on average with more than one male (mean $=2.7$, range $1-5$ ), and the difference between female morphotypes also approached significance (anadromous mean $=3.17 \pm 0.35 \mathrm{SE}$, freshwater mean $=2.34$ $\pm 0.44 \mathrm{SE}, p=0.070$; proportion of variance explained by pond $=0.059$ ). Whilst anadromous females may be more promiscuous than freshwater females, this result may be partially due to our sampling methodology (as the number of fry sampled from a given female increases we are more likely to detect additional mates).

\section{Likelihood Model —Mating Events (Table 1)}

The full 12 parameter model of observed mating events had a log likelihood score of -85.57 . Allowing the estimated assortative mating coefficient, $I$, to vary across the four ponds $\left(I_{\mathrm{A}}-I_{\mathrm{D}}\right)$ did not significantly improve the likelihood of the model $(\Delta \log L=0.70,3$ d.f.) so these parameters were pooled. Similarly, the relative mating propensity of freshwater males $\left(v_{\mathrm{FW}}\right)$ was pooled across ponds $(\Delta \log L=3.18,3$ d.f.), further reducing the model to 6 parameters (Figure 1a). Fixing the level of assortative mating to 0 and the relative mating propensity of freshwater males to 1 did not significantly decrease the likelihood of the observed data $(\Delta \log L=2.19,2$ d.f.; Figure 1a); thus, the four remaining parameters explaining significant variation in the observed distribution of mating events were the relative mating propensities of freshwater females in each pond. In ponds $B$ and $D$ the relative mating propensity of freshwater females was less than $22 \%$ of anadromous female mating propensity. In contrast, in ponds $A$ and $C$ the relative mating propensity of freshwater females did not differ significantly from that of anadromous females.

\section{Likelihood Model —Number of Fry (Table 1)}

The full 12 parameter model was the most likely model for the observed number of fry $\log L=-396.618$, Figure $1 \mathrm{~b}$ ), since constraining parameters across ponds or removing them entirely resulted in significantly less likely models (pooling $I: \Delta \log L=5.68,3$ d.f.; pooling $v_{\mathrm{FW}}: \Delta \log L=29.623,3$ d.f.; pooling $w_{\mathrm{FW}}: \Delta \log L$ $=31.517,3$ d.f.). In ponds $A$ and $D$, the estimated assortative mating parameter was significantly greater 
than zero, although these estimates were low $\left(I_{\mathrm{A}}=0.04, I_{\mathrm{D}}=0.05\right)$. In most ponds, the relative mating propensity of freshwater males and females was much less than their anadromous counterparts (mean $v_{\mathrm{FW}}=38 \%$, mean $\left.w_{\mathrm{FW}}=23 \%\right)$.

Figure 1. Estimates of assortative mating ( $I$, white squares) and relative mating propensities (males $(v)$ white bars, females ( $w$ ) grey bars) based on maximum likelihood models of (a) observed mating events and (b) observed number of fry. Error bars represent 95\% confidence intervals. Parameters with black bars and square parentheses were fixed to 1. AN and FW represent anadromous and freshwater morphotypes, and A-D denote pond.

(a) Mating Events

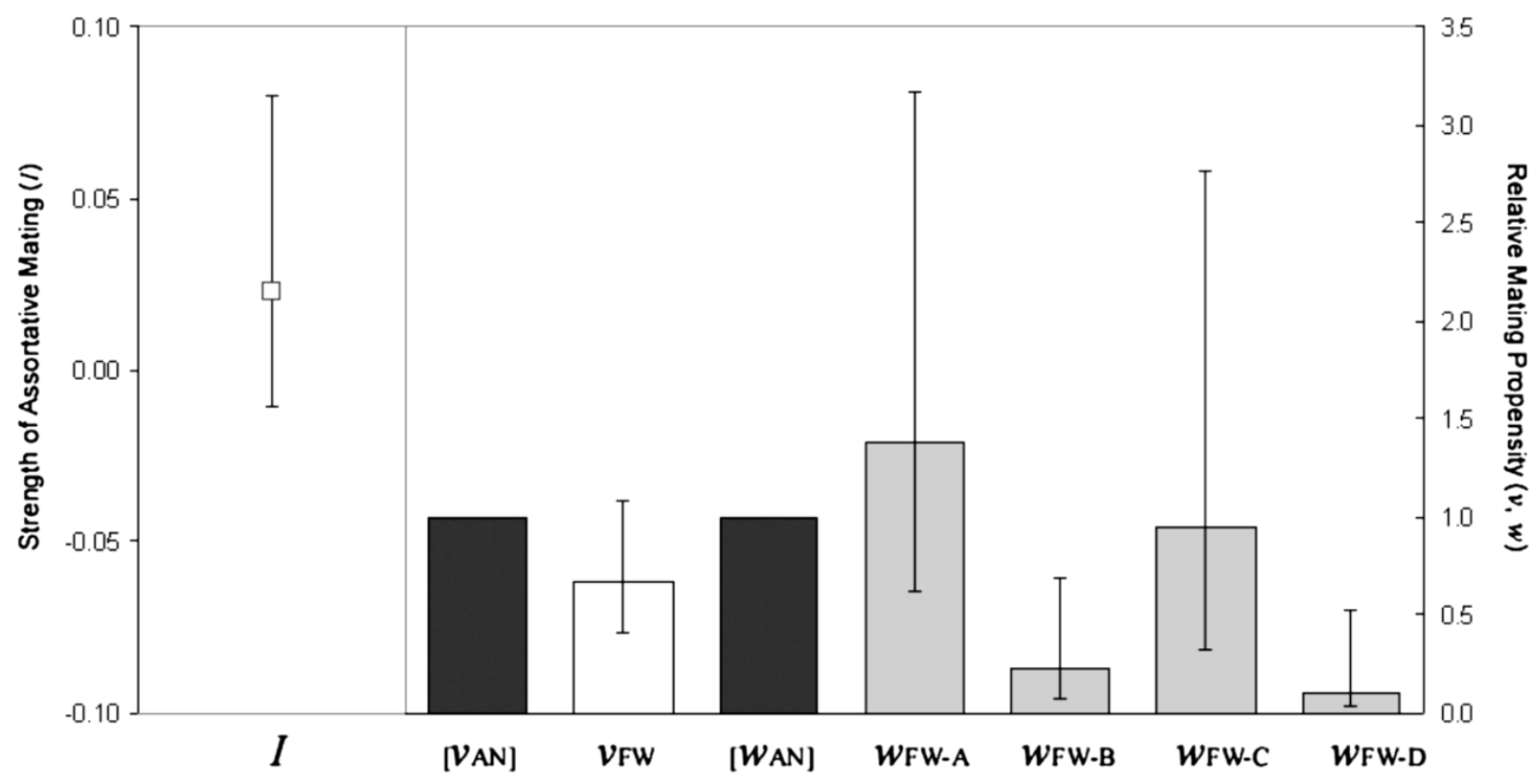

(b) Number of Fry

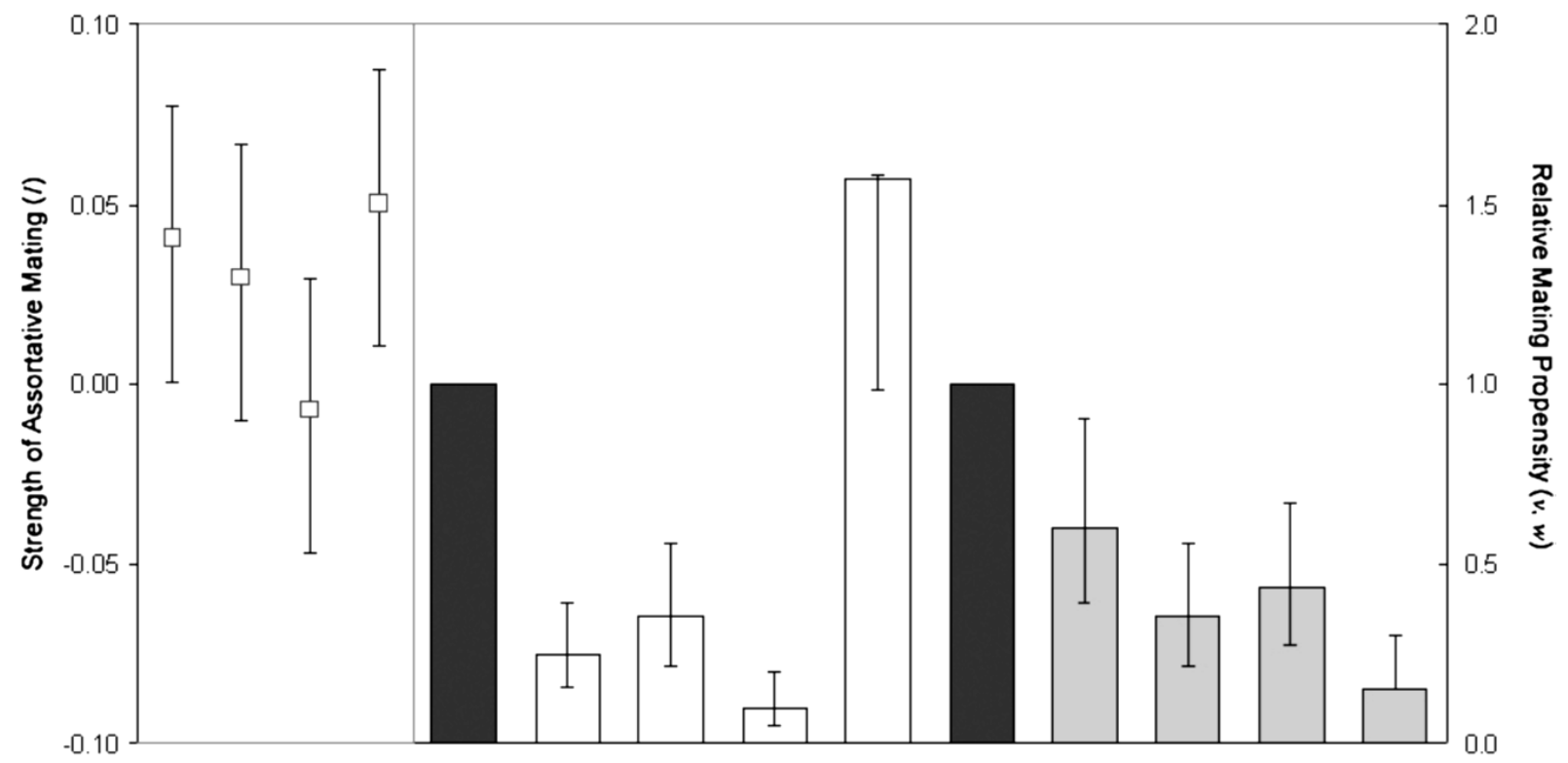

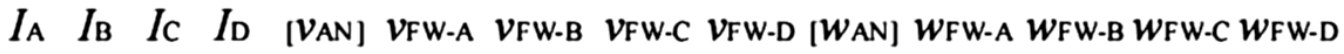


Test for size assortative mating: parental body size

There were no differences in the standard length of candidate parents between ponds $\left(F_{3,49}=2.299, p=\right.$ 0.089). An interaction between sex and morphotype was significant $\left(F_{1,49}=5.524, p=0.023\right)$, but all other interactions were not. Post-hoc tests showed anadromous females were significantly longer than anadromous males (Fisher's PLSD mean difference $=4.769$, critical difference $=3.609, p=0.012$ ), but no significant difference in the standard length of freshwater females and males was detected (Fisher's PLSD mean difference $=-2.313$, critical difference $=5.065, p=0.355$ ).

We found evidence that mating events were associated with male size. A significant interaction between female standard length and female morphotype was detected $\left(F_{1,20}=5.400, p=0.031\right)$, but no other significant effects were observed (proportion of variation explained by pond as a random effect was 0.138). Freshwater females mated with large males independent of their own standard length, but a strong negative relationship between anadromous female standard length and 'preference' for male size was detected. Small anadromous females mated with larger males than did large anadromous females (Figure 2).

Figure 2. Association between female size preference and female standard length. Black squares and solid line $=$ anadromous females, white circles and dashed line $=$ freshwater females. Preference score $>0$ signifies a preference for large males, whilst a preference score $<0$ signifies a preference for small males.

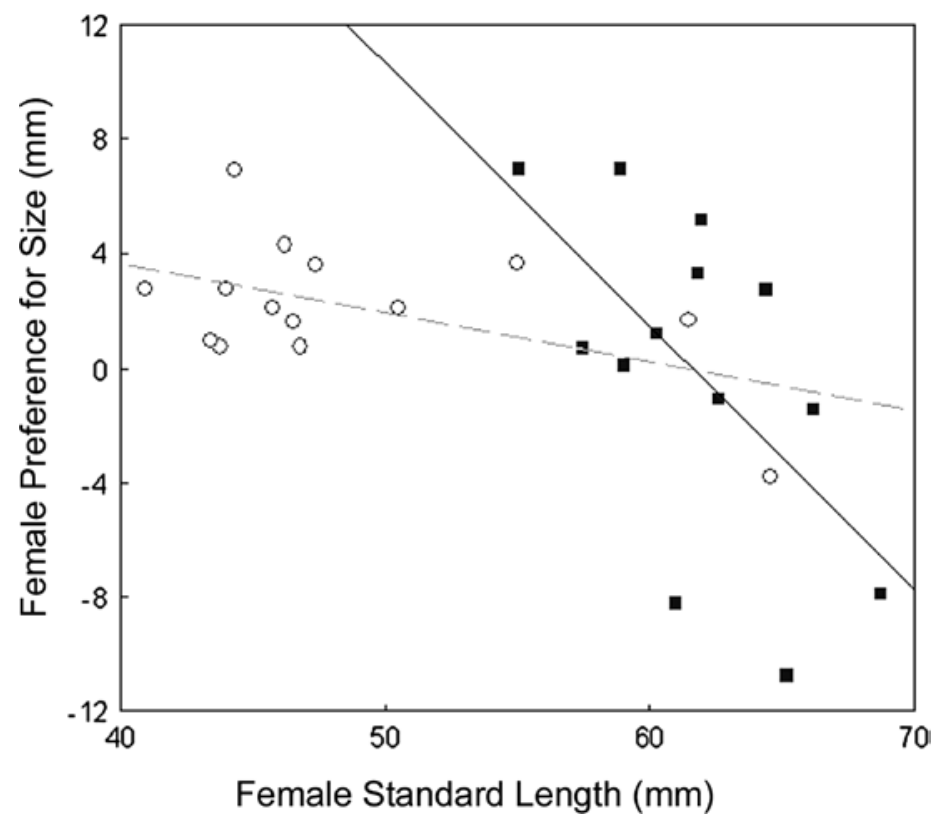

\section{Discussion}

Our analysis of mating events suggests that anadromous and freshwater morphs mate randomly with respect to morphotype when living in sympatry. The lack of observed assortative mating explains the prevalence of intermediate morphotypes in the wild, is consistent with the Hagen's (1967) study of sticklebacks in the Little Campbell River, but contrasts with the finding of assortative mate preference in several populations used in previous studies (e.g., McKinnon et al., 2004; Scott, 2004). There are two possible explanations for the contrasting findings of studies and the importance of divergent sexual selection: Firstly, divergent sexual selection may exist, but may be obscured in some populations by ecological factors such as territoriality (or others mentioned in the Introduction). Secondly, sexual selection may operate on ecologically divergent traits such as body size (McKinnon et al., 2004), and the 
divergence in body size between anadromous and freshwater sticklebacks in the River Tyne population may be relatively small. Either way, the findings of the present study suggest that divergent mate choice is unlikely to contribute significantly to premating reproductive isolation between anadromous and freshwater sticklebacks in the River Tyne, Scotland.

Owing to our experimental design, we were unable to investigate differences in male courtship, territoriality or paternal care, but this was not part of our aim. Rather, in these ponds, we hoped to produce controlled, semi-natural conditions, to get a better idea of the strength of assortative mating that occurs in sympatric wild populations where factors such as territory defence, sneaky mating and paternal care are likely to influence reproductive isolation between anadromous and freshwater sticklebacks. Implicit in this design and the conclusions drawn from it, is the assumption that the conditions provided reflect conditions in the wild (e.g., nesting substrate, density and ratio of anadromous and freshwater fish). Owing to the paucity of data on anadromous-freshwater interactions in sympatric wild populations, the validity of this assumption is unknown. Thus, as with any other experiment, our findings of no assortative mating between sympatric anadromous and freshwater sticklebacks must be interpreted with the experimental conditions in mind. However, by using morphotypes collected from a single sympatric breeding site rather than allopatric sites, genetics to determine actual mating events rather than behavioural indicators of mate choice, and by allowing interactions between multiple males and females, we argue our experiment furthers the understanding of premating reproductive isolation between anadromous and freshwater sticklebacks.

Matings between morphotypes in ponds $A$ and $D$ produced fewer fry than matings within morphotype. The finding of significant assortative mating in this analysis is distinct from the previous analysis of mating events because, as mentioned in the methods above, the estimate of assortative mating based on number of fry might also explain variation due to hybrid zygote or hybrid fry mortality. Thus, the finding of significant assortative mating in this analysis (albeit weak) and not in the former analysis is interesting because it provides evidence of possible postmating isolation. Either endogenous (genetic incompatibilities) or exogenous (environmental) factors could influence the survival of hybrid zygotes or fry, however, because this effect was detected in only two of the four ponds ( $A$ and $D$ ), exogenous factors are more likely to be responsible. All adults used were sexually active (had secondary sexual characteristics) at the start of the experiment, and are also active over a similar time frame in the wild (Jones et al., 2006). Fry sampled from within form matings did not differ significantly in standard length from fry sampled from between form matings $\left(F_{2,329}=0.108, p=0.897\right.$; mean standard length of hybrid fry $=0.982$, anadromous fry $=0.993$, freshwater fry $=1.002$ ) and, therefore, assuming growth rates are similar, we have no reason to expect that hybrid fry were exposed to a greater period of selection than non-hybrids. Matings between anadromous and freshwater sticklebacks from the Little Campbell River showed no evidence of genetic incompatibilities or reduced viability (Hagen, 1967). Exogenous factors influencing postmating isolation between anadromous and freshwater sticklebacks have been implicated (McKinnon \& Rundle, 2002) but not yet proven, and may continue to act on hybrids beyond the age of those tested in this experiment.

The theory of reinforcement (Dobzhansky, 1951) predicts that when mechanisms of postmating isolation exist in sympatric populations, it may be adaptive for incipient species to evolve premating barriers to gene flow to avoid the production of hybrid offspring. Premating barriers may also evolve as a side-effect of ecological adaptation to alternative niches. For example, divergent ecological selection may act on traits which are used in mate choice. Contact zones between anadromous and freshwater sticklebacks occur along environmental gradients making the evolution of premating isolation by both mechanisms possible (and these are not mutually exclusive). However, in a hybrid zone along an environmental gradient the two mechanisms may result in fundamentally different patterns of isolation. If reinforcement 
was primarily driving the evolution of premating isolation, then premating isolation would be strongest in the centre of the hybrid zone where the production of hybrid offspring was most likely to occur. However, if premating isolation evolved as a consequence of ecological selection, then it might be strongest between individuals from divergent environments and weakest between those with similar environments. In the present study we found no evidence of assortative mating, suggesting that reinforcement is not driving the evolution of premating isolation. Rather, our findings are more consistent with divergent ecological selection driving isolating barriers, in so far as, individuals from identical ecological conditions (i.e., sympatry) showed no evidence of assortative mating.

Previous studies have shown that assortative mating occurs between sticklebacks from divergent ecological conditions (Nagel \& Schluter, 1998; Boughman et al., 2005; Vines \& Schluter, 2006), and that this assortative mating is primarily associated with size (McKinnon et al., 2004). Mating events were associated with body size but size-assortative mating did not occur. Both anadromous and freshwater females mated with large males more often than small males, however, a significant interaction was observed where large anadromous females mated with small males, whilst small anadromous females mated with large males. The 'preference' for large males is consistent with studies conducted within stickleback populations of a single morphotype (e.g., Rowland, 1989b; Kraak et al., 1999) but contrary to studies of divergent stickleback populations where differences in body size were negatively associated with mate compatibility (Nagel \& Schluter, 1998; McKinnon et al., 2004; Boughman et al., 2005). One possible explanation might be that the difference in size between morphotypes in the River Tyne sample is relatively low compared to variation in size in populations described by McKinnon et al. (2004). However, sticklebacks in the Little Campbell River show larger divergence in size than those used in this study, and yet Hagen (1967) did not detect significant assortative mate choice in Little Campbell River. Similarly, divergence in size in populations of sticklebacks studied by Nagel \& Schluter (1998) is smaller than that of River Tyne sticklebacks and yet positive assortative mate choice was detected. River Tyne fish do, however, appear to be unusual in the extent of sexual dimorphism observed within anadromous morphotypes (females are longer than males by approximately $5 \mathrm{~mm}$ ). In populations where size assortative mating has been detected, limited sexual dimorphism in anadromous fish is commonly observed (J. McKinnon, pers. commun.). Size sexual dimorphism in River Tyne fish may result in a lack of size assortative mating, since size may not be a reliable cue for an individual distinguishing conspecifics from heterospecifics.

Perhaps a more likely explanation for the lack of size assortative mating in the present experiment might be differential success by large and small males in obtaining and holding territories within each pond (Rowland, 1983). Previous studies did not investigate this (Nagel \& Schluter, 1998; McKinnon et al., 2004). If large males out-competed smaller males for nesting territory, this may have resulted in asymmetrical female choice with regards to male body size. Further, the observation that large anadromous females mated with small males, whilst small anadromous females mated with large males may be due to large females actively choosing to mate with small males, or more likely, small males might be adopting a sneaky mating strategy and this strategy may be more successful in matings involving large females because of the larger clutch size (Kraak \& Bakker, 1998). We hypothesise that the prevalence of matings with large males may cause the direction of hybridisation in the wild to be asymmetrical, occurring more often between freshwater females and anadromous males.

One fundamental assumption of our approach is that the classification of adults based on morphotype reflects their true genetic ancestry. This is important because morphology can be an unreliable predictor of ancestral origin in a hybrid zone (e.g., Goodman et al., 1999). We aimed to reduce this error by using multiple morphological traits rather than relying on a single trait to classify individuals. Using three morphological traits (standard length, plate number and keel presence/absence), a discriminant function 
analysis was able to assign individuals to the correct genetic group $92 \%$ of the time (F.C.J., unpublished data). Therefore, the adult morphotypes we selected for this pond experiment are very likely to have the assumed anadromous and freshwater genetic ancestry.

In sympatric populations of Drosophila sister species, prezygotic isolation appears to evolve faster than postzygotic isolation (Coyne \& Orr, 1997). Similarly, observations of incipient passion-vine butterfly species (Heliconius erato and $\mathrm{H}$. himera) have revealed that assortative mate choice has preceded the evolution of genetic incompatibilities (McMillan et al., 1997), and this is thought to be due to strong environmental selection against hybrids (i.e., reinforcement; Mallet et al., 1998). The lack of assortative mating between divergent anadromous and freshwater sticklebacks in this study and the absence of genetic compatibilities in other studies (McPhail, 1994), suggests that the divergence between anadromous and freshwater morphotypes is likely to be maintained by ecology-dependent postmating barriers. Our finding of relatively weak postmating isolation may explain why hybrid inferiority has not yet reinforced (Dobzhansky, 1951) divergent mate choice barriers in the River Tyne.

\section{Acknowledgements}

The authors would like to thank Jeff McKinnon, Josephine Pemberton, Chris Jiggins and Mike Ritchie for their comments on previous versions of this manuscript. Financial support was provided by The University of Edinburgh, College of Science and Engineering and School of Biological Sciences, an Overseas Research Scholarship, and the Royal Society of London.

\section{References}

Bailey, R.I., Thomas, C.D. \& Butlin, R.K. (2004). Premating barriers to gene exchange and their implications for the structure of a mosaic hybrid zone between Chorthippus brunneus and $C$. jacobsi (Orthoptera: Acrididae). — J. Evol. Biol. 17: 108-119.

Barber, I., Arnott, S.A., Braithwaite, V.A., Andrew, J. \& Huntingford, F.A. (2001). Indirect fitness consequences of mate choice in sticklebacks: offspring of brighter males grow slowly but resist parasitic infections. —Proc. Roy. Soc. Lond. B Biol. 268: 71-76.

Boughman, J.W., Rundle, H.D. \& Schluter, D. (2005). Parallel evolution of sexual isolation in sticklebacks. — Evolution 59: 361-373.

Butlin, R. (1998). What do hybrid zones in general, and the Chorthippus parallelus zone in particular, tell us about speciation? - In: Endless forms species and speciation (Howard, D.J. \& Berlocher, S.H., eds). Oxford University Press, Oxford, p. 367-378.

Caillaud, M.C. \& Via, S. (2000). Specialized feeding behaviour influences both ecological specialization and assortative mating in sympatric host races of pea aphids.-Am. Nat. 156: 606-621.

Coyne, J.A. \& Orr, H.A. (1997). "Patterns of speciation in Drosophila" revisited. - Evolution 51: 295-303.

Cruz, R., Carballo, M., Conde-Padin, P. \& Rolan-Alvarez, E. (2004). Testing alternative models for sexual isolation in natural populations of Littorina saxatilis: indirect support for by-product ecological speciation?

— J. Evol. Biol. 17: 288-293. 
Davies, N., Aiello, A., Mallet, J., Pomiankowski, A. \& Silberglied, R.E. (1997). Speciation in two neotropical butterflies: extending Haldane's rule. — Proc. Roy. Soc. Lond. B Biol. 264: 845-851.

Dobzhansky, T. (1951). Genetics and the origin of species. - Columbia University Press, New York, NY.

Duchesne, P., Godbout, M.H. \& Bernatchez, L. (2002). PAPA (package for the analysis of parental allocation): a computer program for simulated and real parental allocation. - Mol. Ecol. Notes 2: 191193.

Edwards, A.W.F. (1972). Likelihood. - Cambridge University Press, Cambridge.

Endler, J.A. (1992). Signals, signal conditions, and the direction of evolution. - Am. Nat. 139: S125S153.

Gee, J.M. (2003). How a hybrid zone is maintained: behavioural mechanisms of interbreeding between California and Gambel's Quail (Callipepla californica and C. gambelii). — Evolution 57: 2407-2415.

Goodman, S.J., Barton, N.H., Swanson, G., Abernethy, K. \& Pemberton, J.M. (1999). Introgression through rare hybridization: a genetic study of a hybrid zone between red and sika deer (genus Cervus) in Argyll, Scotland. - Genetics 152: 355-371.

Haavie, J., Borge, T., Bures, S., Garamszegi, L.Z., Lampe, H.M., Moreno, J., Qvarnstrom, A., Torok, J. \& Saetre, G.P. (2004). Flycatcher song in allopatry and sympatry - convergence, divergence and reinforcement. - J. Evol. Biol. 17: 227-237.

Hagen, D.W. (1967). Isolating mechanisms in threespine sticklebacks (Gasterosteus). - J. Fish. Res. Board Can. 24: 1637-1692.

Hay, D.E. \& McPhail, J.D. (1975). Mate selection in threespine sticklebacks (Gasterosteus). - Can. J. Zool.-Rev. Can. Zool. 53: 441-450.

Hill, G.E. (1999). Is there an immunological cost to carotenoid-based ornamental coloration? - Am. Nat. 154: 589-595.

Houde, A.E. \& Endler, J.A. (1990). Correlated evolution of female mating preferences and male color patterns in the guppy Poecilia reticulata. -Science 248: 1405-1408.

Ishikawa, M. \& Mori, S. (2000). Mating success and male courtship behaviours in three populations of the threespine stickleback. - Behaviour 137: 1065-1080.

Jones, F.C., Brown, C., Pemberton, J.M. \& Braithwaite, V.A. (2006). Reproductive isolation in a threespine stickleback hybrid zone.- J. Evol. Biol. 19: 1531-1544.

Kelley, J.L., Graves, J.A. \& Magurran, A.E. (1999). Familiarity breeds contempt in guppies. — Nature 401: 661-662.

Kirkpatrick, M. \& Ravigne, V. (2002). Speciation by natural and sexual selection: models and experiments._- Am. Nat. 159: S22-S35.

Kraak, S.B.M. \& Bakker, T.C.M. (1998).Mutual mate choice in sticklebacks: attractive males choose big females, which lay big eggs.- Anim. Behav. 56: 859-866. 
Kraak, S.B.M., Bakker, T.C.M. \& Mundwiler, B. (1999). Sexual selection in sticklebacks in the field: correlates of reproductive, mating, and paternal success. - Behav. Ecol. 10: 696-706.

Largiader, C.R., Fries, V. \& Bakker, T.C.M. (2001). Genetic analysis of sneaking and egg-thievery in a natural population of the three-spined stickleback (Gasterosteus aculeatus L.).-Heredity 86: 459-468.

Magurran, A.E. \& Ramnarine, I.W. (2004). Learned mate recognition and reproductive isolation in guppies. - Anim. Behav. 67: 1077-1082.

Mallet, J.,McMillan,W.O. \& Jiggins, C.D. (1998). Estimating the mating behaviour of a pair of hybridizing Heliconius species in the wild. — Evolution 52: 503-510.

Mayr, E. (1942). Systematics and the origin of species. - Columbia University Press, New York, NY.

McKinnon, J. \& Rundle, H.D. (2002). Speciation in nature: the threespine stickleback model systems.Trends Ecol. Evol. 17: 480-488.

McKinnon, J.S. (1996). Red coloration and male parental behaviour in the threespine stickleback. - J. Fish Biol. 49: 1030-1033.

McKinnon, J.S., Mori, S., Blackman, B.K., David, L., Kingsley, D.M., Jamieson, L., Chou, J. \& Schluter, D. (2004). Evidence for ecology's role in speciation.—Nature 429: 294-298.

McMillan, W.O., Jiggins, C.D. \& Mallet, J. (1997). What initiates speciation in passion-vine butterflies? Proc. Natl. Acad. Sci. USA 94: 8628-8633.

McPhail, J.D. (1994). Speciation and the evolution of reproductive isolation in the sticklebacks (Gasterosteus) of south-western British Columbia. - In: Evolutionary biology of the threespine stickleback (Bell, M.A. \& Foster, S.A., eds). Oxford University Press, Oxford, p. 399-437.

McPhail, J.D. \& Hay, D.E. (1983). Differences in male courtship in fresh-water and marine sticklebacks (Gasterosteus aculeatus). —Can. J. Zool.-Rev. Can. Zool. 61: 292-297.

Milinski, M. \& Bakker, T.C.M. (1990). Female sticklebacks use male coloration in mate choice and hence avoid parasitized males. —Nature 344: 330-333.

Nagel, L. \& Schluter, D. (1998). Body size, natural selection, and speciation in sticklebacks. - Evolution 52: $209-218$.

Nosil, P., Vines, T.H. \& Funk, D.J. (2005). Perspective: reproductive isolation caused by natural selection against immigrants from divergent habitats.-Evolution 59: 705-719.

Patten, M.A., Rotenberry, J.T. \& Zuk, M. (2004). Habitat selection, acoustic adaptation, and the evolution of reproductive isolation. - Evolution 58: 2144-2155.

Peake, T.M. \&McGregor, P.K. (2004). Information and aggression in fishes._Learn. Behav. 32: 114-121.

Peichel, C.L., Nereng, K.S., Ohgi, K.A., Colem, B.L.E., Colosimo, P.F., Buerkle, C.A., Schluter, D. \& Kingsley, D.M. (2001). The genetic architecture of divergence between threespine stickleback species. Nature 414: 901-905. 
Reichard, M., Bryja, J., Ondrackova, M., Davidova, M., Kaniewska, P. \& Smith, C. (2005). Sexual selection for male dominance reduces opportunities for female mate choice in the European bitterling (Rhodeus sericeus).- Mol. Ecol. 14: 1533-1542.

Reusch, T.B.H., Haberli, M.A., Aeschlimann, P.B. \& Milinski, M. (2001). Female sticklebacks count alleles in a strategy of sexual selection explaining MHC polymorphism. - Nature 414: 300-302.

Rowland, W.J. (1983). Interspecific aggression and dominance in Gasterosteus. — Environ. Biol. Fishes 8: $269-277$.

Rowland,W.J. (1989a). The ethological basis of mate choice in male threespine sticklebacks, Gasterosteus aculeatus. -Anim. Behav. 38: 112-120.

Rowland, W.J. (1989b). Mate choice and the supernormality effect in female sticklebacks (Gasterosteus aculeatus). - Behav. Ecol. Sociobiol. 24: 433-438.

Rundle, H.D. \& Schluter, D. (1998). Reinforcement of stickleback mate preferences: sympatry breeds contempt. —Evolution 52: 200-208.

Scott, R.J. (2004). Assortative mating between adjacent populations of threespine stickleback (Gasterosteus aculeatus). - Ecol. Freshw. Fish 13: 1-7.

Sokal, R.R. \& Rohlf, F.J. (1995). Biometry.-W.H. Freeman, New York, NY.

Szymura, J.M. \& Barton, N.H. (1986). Genetic-analysis of a hybrid zone between the fire-bellied toads, Bombina bombina and Bombina variegata, near Cracow in Southern Poland. —Evolution 40: 1141-1159.

Taylor, E.B. (1998). Microsatellites isolated from the threespine stickleback Gasterosteus aculeatus. Mol. Ecol. 7: 930-931.

Tregenza, T., Pritchard, V.L. \& Butlin, R.K. (2000). The origins of premating reproductive isolation: testing hypotheses in the grasshopper Chorthippus parallelus. - Evolution 54: 1687-1698.

Vines, T.H. \& Schluter, D. (2006). Strong assortative mating between allopatric sticklebacks as a byproduct of adaptation to different environments.—Proc. Roy. Soc. B. Biol. 273: 911-916.

Walsh, P.S., Metzger, D.A. \& Higuchi, R. (1991). Chelex-100 as a medium for simple extraction of DNA for PCR-based typing from forensic material. — Biotechniques 10: 506-513.

Ward, A.J.W., Hart, P.J.B. \& Krause, J. (2004). The effects of habitat- and diet-based cues on association preferences in three-spined sticklebacks. —Behav. Ecol. 15: 925-929.

Zar, J.H. (1998). Biostatistical analysis. — Prentice-Hall, London.

Ziuganov, V.V. (1995). Reproductive isolation among lateral plate phenotypes (low, partial, complete) of the threespine stickleback, Gasterosteus aculeatus, from the White Sea basin and the Kamchatka Peninsula, Russia. — Behaviour 132: 1173-1181. 


\section{Appendix A}

\section{Genotyping methods}

Alleles at each of eight microsatellite loci (Table A1) were amplified using polymerase chain reactions (PCR) containing $1 \mathrm{mM}$ dNTPs, $0.4 \mu \mathrm{M}$ of each primer, 0.4 units of BioLine Taq polymerase, $1 \times$ BioLine Buffer, $2.0 \mu \mathrm{l}$ of DNA and varying $\mathrm{MgCl}_{2}$ concentrations (Table A1). Amplification cycles consisted of 2 min denaturation at $94^{\circ} \mathrm{C}$, followed by 25 cycles of $30 \mathrm{~s}$ at annealing temperature (Table A1), $1 \mathrm{~min}$ at $72^{\circ} \mathrm{C}$ and $45 \mathrm{~S}$ at $90^{\circ} \mathrm{C}$, and finished with 4 min extension at $72^{\circ} \mathrm{C}$. PCR products were run with internal size standard (GS-500-LIZ) on an ABI 3730 capillary sequencer and analysed using Genemapper software v3.0 (ABI).

Table A1. Details of loci used to assign parentage.

\begin{tabular}{|c|c|c|c|c|c|}
\hline \multirow{2}{*}{\multicolumn{3}{|c|}{ Locus Primer sequence (', $\left.{ }^{*} 5{ }^{\prime}-3^{\prime}\right)$}} & Allele size range (bp) & PCR conditions ${ }^{a}$ & Reference \\
\hline \multicolumn{5}{|c|}{ Microsatellite loci } & \\
\hline \multirow[t]{2}{*}{ STN26 } & $\mathrm{F}$ & *GTATCGAAGTCTGAAGGCCG & $106-124$ & $60(0.5)$ & 1 \\
\hline & $\mathrm{R}$ & GTACAGCATGTGGTCGATGG & & & \\
\hline \multirow[t]{2}{*}{ STN96 } & $\mathrm{F}$ & * ACACCTTCGGCTCCATATCC & $218-278$ & $58(3.0)$ & 1 \\
\hline & $\mathrm{R}$ & CGCAGCTCTCTGCTTTGC & & & \\
\hline \multirow[t]{2}{*}{ STN130 } & $\mathrm{F}$ & ^TTCGGCTTATTTTCTTACCTGC & $116-154$ & $59(0.5)$ & 1 \\
\hline & $\mathrm{R}$ & ATGTTGTAGGCGAGGACAGGATG & & & \\
\hline \multirow{2}{*}{ Gac 3133} & $\mathrm{~F}$ & ${ }^{*}$ CGCCCAGTTCCTGAACTTAG & 127-191 & $56(2.0)$ & 2 \\
\hline & $\mathrm{R}$ & CATGGTGGGCTGACTGAC & & & \\
\hline \multirow[t]{2}{*}{ Gac 4170} & $\mathrm{~F}$ & ${ }^{*}$ GCCGAGCCACATAGAGA & $102-150$ & $55(0.5)$ & 2 \\
\hline & $\mathrm{R}$ & CCAATATAACAGCCGAGCAG & & & \\
\hline \multirow[t]{2}{*}{ Gac 1097} & $\mathrm{~F}$ & *AGGAACTCTCTTCTTCTCTG & $90-144$ & $55(1.5)$ & 2 \\
\hline & $\mathrm{R}$ & CCCGGGTTAGTCACT & & & \\
\hline \multirow[t]{2}{*}{ Gac 1125} & $\mathrm{~F}$ & ${ }^{*}$ CATCACACCCAGCСТСТC & $149-223$ & $57(2.0)$ & 2 \\
\hline & $\mathrm{R}$ & ССТСССТССААСТСТТАТСА & & & \\
\hline \multirow[t]{2}{*}{ Gac u7 } & $\mathrm{F}$ & ${ }^{*}$ CAAAAGCAACAATCGACAAG & $91-135$ & $56(2.0)$ & 3 \\
\hline & $\mathrm{R}$ & CAATAACTGGAAGAGTGG & & & \\
\hline
\end{tabular}

$\sim^{*}$ Fluorescent label.

${ }^{\text {a }}$ Annealing temperature $\left({ }^{\circ} \mathrm{C}\right)$ and $\mathrm{MgCl}_{2}$ concentration $(\mathrm{mM})$ in parentheses.

References: 1, Peichel et al. (2001); 2, Largiader et al. (2001); 3, Taylor (1998).

\section{Appendix B}

Table B1. The number, sex and morphotype of adults not identified as parents in each pond. Four individuals of each category were introduced to each pond.

\begin{tabular}{|lcccc|}
\hline Sex and morphotype & Pond A & Pond B & Pond C & Pond D \\
\hline Female freshwater & -- & -- & 1 & 2 \\
Female anadromous & -- & -- & 2 & - \\
Male freshwater & -- & 3 & 1 & 2 \\
Male anadromous & 1 & -- & -- & 1 \\
\hline
\end{tabular}




\section{Appendix C}

We used the maximum likelihood algorithm of the PAPA software (Duchesne et al., 2002) for simulations to determine allocation power. To obtain a conservative estimate of expected parentage allocation success, it was assumed that all parental individuals were able to mate with each other (i.e., placed within in a single pond). A transmission error of 0.02 , with even distribution across all alleles, was factored into the simulations at both the production of pseudo-offspring step and the allocation of pseudo-offspring to parents step.

\section{Appendix D}

We used a likelihood approach to investigate assortative mating between morphotypes. Differences in the fecundity or propensity of anadromous and freshwater morphotypes to mate may obscure estimates of the strength of assortative mating. Using a likelihood approach to examine parental mating behaviour (Davies et al., 1997), enabled us to distinguish assortative mating from these effects. Under a null model of no assortative mating and no differences in mating propensity, the expected probability of a mating between a male and a female will be $p_{\mathrm{ii}}=p_{\mathrm{ij}}=p_{\mathrm{ji}}=p_{\mathrm{jj}}=0.25$ (where $\mathrm{i}$ and $\mathrm{j}$ represent anadromous or freshwater morphotype of the male and female respectively). Alternatively, if assortative mating occurs, then mating will deviate from random by a factor $(I)$, and the expected probability of mating between a male and a female will be $p_{\mathrm{ii}}=0.25+I, p_{\mathrm{ij}}=0.25-I, p_{\mathrm{ji}}=0.25-I$ and $p_{\mathrm{jj}}=0.25+I$.

Now consider a situation where the propensity of males of morphotype $\mathrm{j}$ to mate $\left(v_{\mathrm{j}}\right)$ differs relative to that of males of morphotype $\mathrm{i}\left(v_{\mathrm{j}}\right)$ and, similarly, the mating propensity of the alternative female morphotypes also differs $\left(w_{\mathrm{j}}, w_{\mathrm{i}}\right)$. In this case, the expected probability of a mating is listed below.

$$
\begin{aligned}
& p_{\mathrm{ii}}=\left(\frac{v_{\mathrm{i}}}{\left(v_{\mathrm{i}}+v_{\mathrm{j}}\right)}\right)\left(\frac{w_{\mathrm{i}}}{\left(w_{\mathrm{i}}+w_{\mathrm{j}}\right)}\right)+I \\
& p_{\mathrm{ij}}=\left(\frac{v_{\mathrm{i}}}{\left(v_{\mathrm{i}}+v_{\mathrm{j}}\right)}\right)\left(\frac{w_{\mathrm{j}}}{\left(w_{\mathrm{i}}+w_{\mathrm{j}}\right)}\right)-I \\
& p_{\mathrm{ji}}=\left(\frac{v_{\mathrm{j}}}{\left(v_{\mathrm{i}}+v_{\mathrm{j}}\right)}\right)\left(\frac{w_{\mathrm{i}}}{\left(w_{\mathrm{i}}+w_{\mathrm{j}}\right)}\right)-I \\
& p_{\mathrm{jj}}=\left(\frac{v_{\mathrm{j}}}{\left(v_{\mathrm{i}}+v_{\mathrm{j}}\right)}\right)\left(\frac{w_{\mathrm{j}}}{\left(w_{\mathrm{i}}+w_{\mathrm{j}}\right)}\right)+I
\end{aligned}
$$

